\title{
Correction to: A Substance Use Treatment Programme for Mentally III Forensic Patients in an Australian Setting: a Pilot Study of Feasibility, Acceptability and Preliminary Efficacy
}

\author{
Daniel McFadden ${ }^{1,2}$ D $\cdot$ Katrina Prior ${ }^{1} \cdot$ Emma L. Barrett $^{1}$ \\ Published online: 9 October 2020 \\ C) Springer Science+Business Media, LLC, part of Springer Nature 2020
}

\section{Correction to: Int J Ment Health Addiction. https://doi.org/10.1007/s11469-020-00348-3}

The following corrections were needed to this article following its original publication. All corrections refer to information contained in Table 3:

Column 1, row 4 labelled 'Age M (SD)' should all be on one line, as 41.7 (11.09).

The following text in column 1 row 23 should not be indented: 'Age of first alcohol/drug use, $M(\mathrm{SD})^{\prime}$.

The following text in column 1 row 41 should not be indented: 'Main current drug of concern $(n=38)$ '. The following text in column 1 row 44 should be indented: 'Meth/amphetamines $\%(n)$ '. The following text in column 1 row 47 is duplicated and should only appear once: 'Ever sought treatment from a health professional or service for alcohol or other drug use $(n=37)$ '. The following text in column 1 row 48 is duplicated and should only appear once: 'Age first sought treatment from a health professional or service ${ }^{3}, M(S D)^{6}$.

The following text in column 1 row 59 is duplicated and should only appear once: 'Previously participated in the 'psychoeducational addressing substance use' group in the forensic hospital $(n=39), \%(n)^{\prime}$.

The original article has been corrected.

Publisher's Note Springer Nature remains neutral with regard to jurisdictional claims in published maps and institutional affiliations.

The online version of the original article can be found at https://doi.org/10.1007/s11469-020-00348-3

Daniel McFadden

dmcf4572@uni.sydney.edu.au

1 Matilda Centre for Research inMental Health and Substance Use, The University of Sydney, Level 6, Jane Foss Russell building (G02), Sydney, NSW 2006, Australia

2 Justice Health and Forensic Mental Health Network, Sydney, Australia 